\title{
ANALYSIS OF THE POSSIBILITY OF USING LOW SPEED TWO- STROKE DUAL-FUEL ENGINES FOR PROPULSION OF SEA-GOING VESSELS
}

\author{
Mariusz Giernalczyk \\ Gdynia Maritime University, Marine Power Plants Department \\ Morska Street 83, 81-225 Gdynia, Poland \\ tel.: +48585586307 \\ e-mail:m.giernalczyk@wm.umg.edu.pl
}

\begin{abstract}
The use of gas/LNG to supply marine engines in addition to tangible economic benefits is also a method of limiting emissions of harmful substances into the atmosphere and meeting strict environmental protection regulations, especially in special areas.

The technology of supplying liquid and gas fuels (Dual Fuel) is most easily used in four-stroke engines but the highest thermal efficiency is ensured by combustion two-stroke piston engines. However, in the first two-stroke dualfuel engines, the gas supply installation was more complicated than in the four-stroke engine. It resulted, among others from the necessity of compressing the gas to high pressures $(15 \div 30 \mathrm{MPa})$, for which extremely energyconsuming multi-stage compression systems were needed. The complicated technical system is inherently prone to failures, which is why the dual-fuel low-speed two-stroke diesel engines remained for a long period in the design and experimental phase. In recent years, there has been a significant breakthrough thanks to the introduction of new solutions with the possibility of supplying two-stroke engines with low-pressure gas (less than $1.6 \mathrm{MPa}$ ). In recent years, many ships powered by two-stroke, dual-fuel internal combustion engines were commissioned. Some shipowners owning a fleet of $L N G$ carriers with two-stroke diesel engines that so far have been powered only by liquid fuels have decided to adapt them to gas combustion. This required the adaptation of the engine for gas combustion and the expansion of the supply gas fuel system.

This paper is an attempt to analyse the legitimacy of introducing two-stroke, dual-fuel internal combustion engines into the propulsion system and adaptation of engines that are already used to burn gas in them. It presents the changes introduced on one of the LNG gas carriers consisting in adapting the engine to gas combustion through modification of the cylinder head and fuel supply installation. Parameter results of the modified engines obtained during sea trials have been presented. Both advantages and disadvantages resulting from gas combustion have been pointed out. Finally, the possibility of this solution application to other LNG carriers was assessed.
\end{abstract}

Keywords: natural gas, LNG carriers, low speed 2-stroke dual-fuel engines

\section{Introduction}

The most rational way to use the boiled gas (BOG) transported by LNG gas carriers therefore seems to be to supply the main propulsion engines, especially the most efficient thermal combustion piston engines.

This is mainly determined by economic considerations. Unlike liquid fuels, gas prices on global markets have been quite stable for many years, and the cost [US \$] of generating an energy unit [MWh] by a gas-powered engine is much smaller than the most popular heavy fuel IFO 380 . In 2012-2013, the price generation of a power unit from a motor fuelled with liquid heavy fuel exceeded almost three times the price of obtaining the same power when supplied with natural gas. This is illustrated in Fig. 1.

The use of LNG fuel for supplying marine engines in addition to tangible economic benefits is also a method of limiting emissions of harmful substances into the atmosphere and meeting strict environmental protection regulations, especially in special areas. Therefore, the interest of shipowners in the use of dual fuel internal combustion engines for the propulsion of ships was 
extended to not only LNG gas carriers, but also other vessels. Due to the fact that the amount of gas boiled during travel of LNG carriers with the load, and even more during unloaded travel may not be sufficient fully cover the engine's needs, the concept of dual fuel engines dominates here. The Dual Fuel power technology is most easily used in dual-fuel, medium-speed and high-speed engines of both main propulsion and generating sets, in which the evaporated gas is supplied to the engine at low pressure (about $0.5-0.8 \mathrm{MPa}$ ) to the air inlet valves of the individual cylinders and mixed with the air in the combustion chamber.

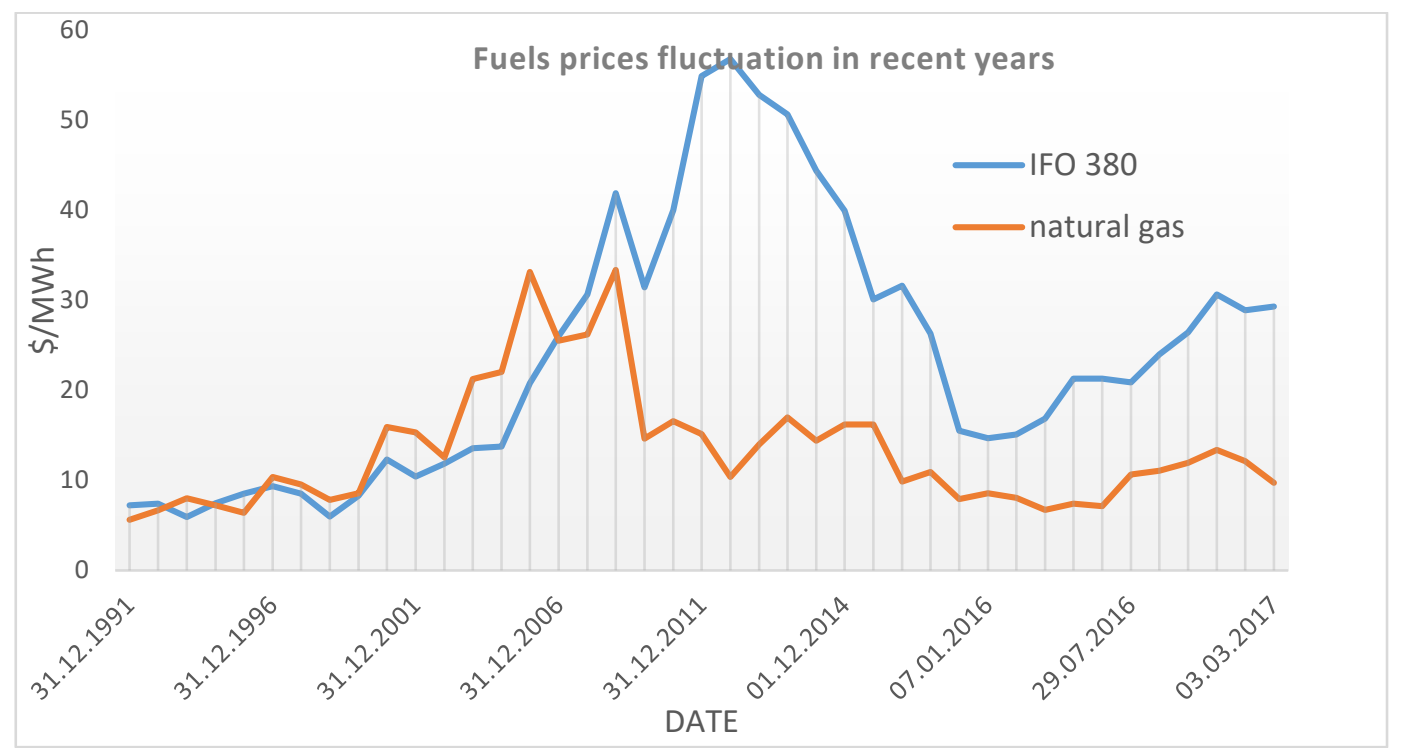

Fig. 1. The volatility of liquid and gas fuels prices and the cost of energy generation in recent years [10]

Currently, many LNG gas carriers are in operation with four-stroke DF engines operating mainly in diesel-electric systems. These include, among others, LNG-carriers BONNY II, FINIMA II with five Wärtsilä 8L50DF engines with a capacity of 7,800 kW each, and many other vessels, such as ships for servicing drilling platforms, passenger ferries, also built by the Gdansk Ship Repair Yard REMONTOWA. Among the ferries with dual fuel engines commissioned in recent years, VIKING GRACE should be mentioned with four Wärtsilä 8L50DF engines with a capacity of $7400 \mathrm{~kW}$ each, or belonging to Fincantiery F.A. GAUTHIER with four Wärtsilä $12 \mathrm{~V} 34 \mathrm{DF}$ engines with $5220 \mathrm{~kW}$ each at a rotational speed of $720 \mathrm{rpm}$ [8].

However, the highest thermal efficiency is obtained with low-speed two-stroke piston engines. That is why, for many years, design and experimental work has been carried out, which led to the creation and introduction of slow-speed two-stroke dual-fuel engines into the propulsion system.

\section{Use of low-speed two-stroke dual-fuel engines for propulsion of ships}

The gas-powered low-speed engine installation is more complex than the medium-speed engine. In the case of ME-GI series engines offered by MAN, it results, among others, from the necessity of compressing the gas to high pressures (15-30 MPa), for which you need extremely energy-consuming multistage compression systems.

The method of supplying liquid (HFO) and gas fuel (LNG) in the ME-GI series engine head is shown in Fig. 2.

The gas injection to the combustion chamber is feasible thanks to the fact that the cylinder head is supplied with the gas injectors together with the ELGI valve (electronic gas injection) (Fig. 2). In order to ensure smooth engine operation on gas, it is essential to provide so-called liquid pilot fuel (i.e. small amount thereof just before the main injection), amounting to $5-8 \%$ of its volume. Research conducted by the manufacturer has proven that without such a pilot injection, 
the engine operates unstably; knocking combustion occurs or there might be even misfiring. The cause of this, among others, is the higher temperature of the vaporized gas' spontaneous combustion [6].

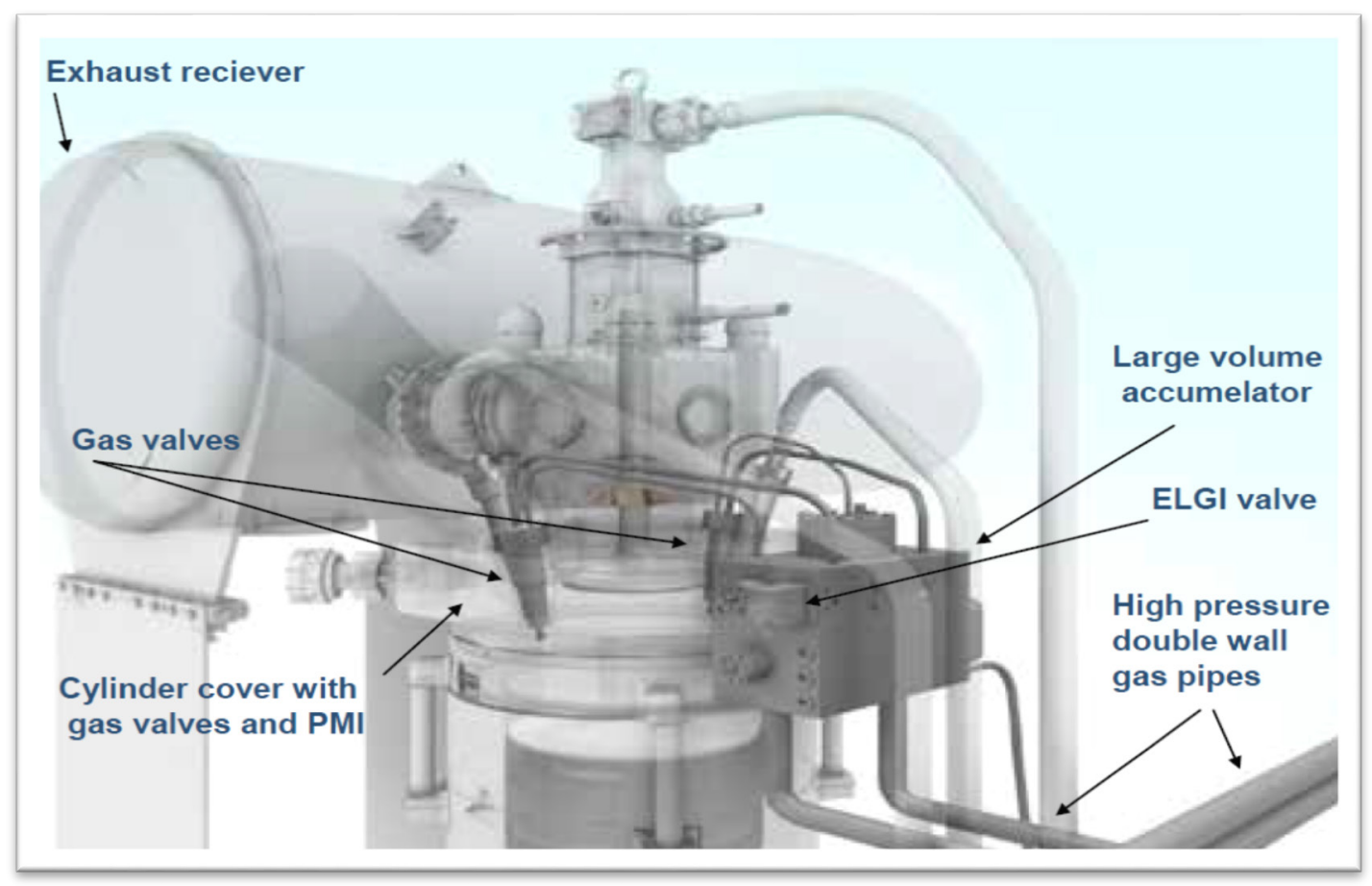

Fig. 2. The way of supplying liquid (HFO) and gas (LNG) fuel in the head of the MAN ME-GI series engine [6]

ME-GI engines, apart from having all the systems widely used in all ME series engines, must be also additionally equipped with a number of other installations, like, among others [6]:

- Ventilation system of the spaces between the interior and exterior compartments of the doublewalled installation fuelling the engine with the vaporized LNG gas,

- Sealing oil system, the aim of which is to separate the gas injection from the pilot fuel dose,

- PLC control unit - comprising of a set of sensors and analysers. Its main function is to turn on and off the gas supply installation. In case of a breakdown, the PLC control unit will automatically switch from gas to the heavy fuel supply without any losses of power in the main engine,

- IGS system (i.e. Inert Gas System) - part of the PLC control unit; its purpose is to keep the main engine supply installation free from gas.

A complex technical system, by its nature, is prone to movement disturbances and other malfunctions. That is a reason why the Dual-Fuel two-stroke Diesel engines for long time had been remaining only in a design-experimental phase. However, after many years of adaptation work, MAN's ME-GI series engines have found applications in the main propulsion of ships, mainly LNG gas carriers. Propelling two-stroke ship engines with natural gas have become possible not only in the case of LNG Carriers but for other types of units too. In 2015, the world's first containership fuelled by LNG called ISLA BELLA has been put into service for TOTE ship owner. What's responsible for supplying the main drive of this unit is the Dual-Fuel low-speed combustion engine - MAN D\&T 8L70ME-C8.2 GI with the power of $21412 \mathrm{~kW}$ at the rotational speed of $98.5 \mathrm{rpm}$. When it comes to the engines responsible for powering the generating sets, these are three Dual-Fuel MAN engines D\&T 9L28/32DF with the power of $1845 \mathrm{~kW}$ each at the rotational speed of $720 \mathrm{rpm}$ [8].

A much simpler gas supply system, requiring significantly lower energy expenditure for the preparation of gas fuel for combustion in the engine, has introduced into operation the new two- 
stroke dual-fuel main drive engines of Wärtsilä's RT-flex DF and Win GD X-DF series. The installation of supplying these engines with gas fuel is low pressure and the gas pressure in the installation does not exceed 1.6 MPa. The method of supplying liquid fuel (in the head) and gas fuel (halfway up the cylinder liner) and the principle of operation of this engine are illustrated in Fig. 3 [10].
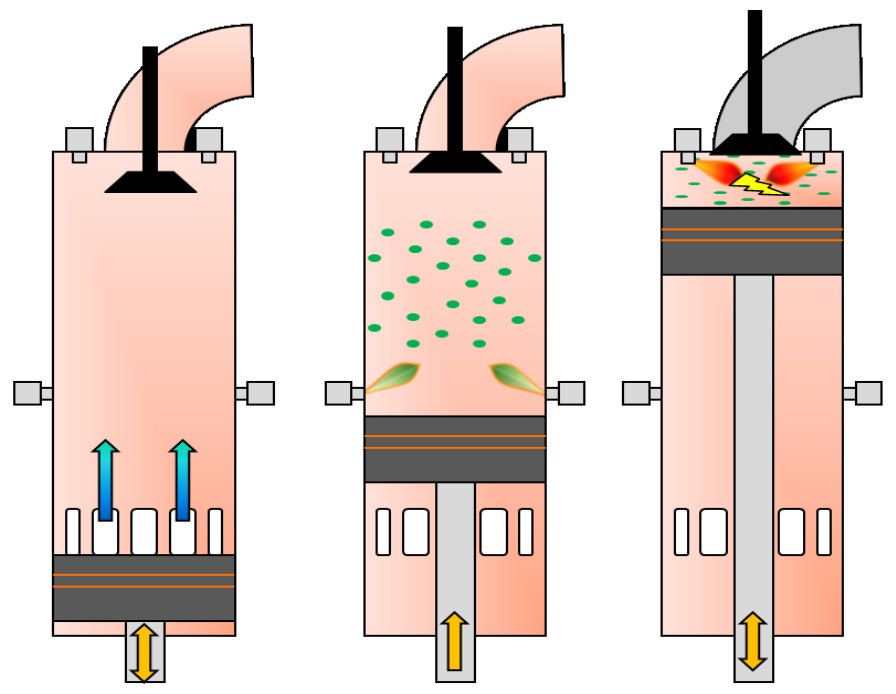

Fig. 3. The principle of operation of the Win GD X series engine in gas mode [10]

The low-pressure gas admission system being pursued by WinGD on its two-stroke DF engines draws on Wärtsilä's long experience with what has become a well-proven industry standard technology. It is based on the lean burn Otto cycle - i.e. ignition of a compressed lean air-gas mixture by injection of a small amount of liquid fuel. Gas admission in the combustion chamber occurs prior to piston compression with low gas feed pressure from 6 bar $(\mathrm{g})$ up to $13.3 \mathrm{bar}(\mathrm{g})$ for bore size up to $72 \mathrm{~cm}$ and $15.0 \mathrm{bar}(\mathrm{g})$ for bore size greater than $72 \mathrm{~cm}$, depending on engine load, gas lower heating value (LHV) and engine rating [11].

The low gas pressure concept used in X-DF engines provides many advantages over the concept high-pressure gas engine, see Tab. 1.

Tab. 1. XDF and high-pressure dual-fuel engine comparison [11]

\begin{tabular}{|l|l|}
\hline \multicolumn{1}{|c|}{ Low-pressure X-DF engines } & \multicolumn{1}{|c|}{ High-pressure gas engines } \\
\hline $\begin{array}{l}\text { Low-pressure gas supply means low investment } \\
\text { costs for the Fuel Gas Supply System (FGSS), low } \\
\text { electrical power consumption and low maintenance } \\
\text { costs }\end{array}$ & $\begin{array}{l}\text { High-pressure gas supply means more expensive } \\
\text { Fuel Gas Supply System (compressors and/or } \\
\text { pumps, components etc.), higher electrical energy } \\
\text { consumption and higher maintenance costs }\end{array}$ \\
\hline $\begin{array}{l}\text { Pilot fuel quantity well below 1\% of total heat } \\
\text { release at nominal engine power }\end{array}$ & $\begin{array}{l}\text { Pilot fuel quantity more than 3\% of total heat } \\
\text { release at nominal engine power }\end{array}$ \\
\hline $\begin{array}{l}\text { X-DF engines can be operated on gas down to 5\% } \\
\text { power. Start/stop and manoeuvring is required in } \\
\text { diesel mode by class rules }\end{array}$ & $\begin{array}{l}\text { High-pressure gas engines can only be operated } \\
\text { when engine power is above 10\% in gas mode }\end{array}$ \\
\hline $\begin{array}{l}\text { Low NOX emissions, Tier III compliant are ECAs } \\
\text { without exhaust gas treatment system }\end{array}$ & $\begin{array}{l}\text { Tier II compliant and an exhaust gas treatment } \\
\text { system like EGR or SCR is needed for Tier III } \\
\text { compliance }\end{array}$ \\
\hline $\begin{array}{l}\text { Particulate matter emissions are significantly } \\
\text { reduced compared to diesel engines }\end{array}$ & Particulate matter emissions still significant \\
\hline
\end{tabular}

Launched at the end of December 2015 the tanker of the Swedish ship-owner Terntank is the first unit equipped with a 5RT-Flex 50DF engine powered by gas in a low-pressure installation. In 
recent years, several new gas carriers equipped with main propulsion for WinGD engines have been commissioned, including three sister ships Marvel Hawk, Marvel Kite and Marvel Falcon built for NYK Line. Each of these ships is powered by two WinGD type 6 X62 DF engines with a capacity of $12,540 \mathrm{~kW}$ each [8].

The benefits of using dual-fuel two-stroke engines fuelled with LNG natural gas have extended the manufacturers' offer to include engines with the possibility of LPG fuelling. This is an offer dedicated mainly to LPG gas carriers, where the evaporated gas to the main drive can be used instead of its re-condensing. In 2013, MAN Energy Solutions announced the development of a new MAN B\&W ME-LGI dual-fuel engine. The engine expands the company's dual-fuel portfolio, enabling the use of more sustainable fuels such as methanol, ethanol and Liquefied Petroleum Gas (LPG).These engines have a low pressure supply system, and the fuel injection takes place under high pressure which was used in the ME series engine while burning HFO liquid fuels. This is possible thanks to the use of a pressure amplifier in front of the ME-LGI series engine, which allows to lower the pressure in the supply system and later to inject into the combustion chamber under the required higher pressure of 500-600 bar. In the case of ME-GI engines powered by LNG gas, a high-pressure feed system is required that immediately allows the required injection pressure of 300 bar at methane and 380 bar at the ethane supply.

In 2013 a series of gas carriers with a capacity of 50 thousand DWT with methanol-powered engines ordered Waterfront Shipping. The first vessel of this series powered by the 6G50ME-LGI engine is Lindanger commissioned in April 2016.

\section{Possibilities of adjusting a two-stroke combustion engine powered with liquid fuel to supply LNG}

In 2005, the MAN Company signed a contract with Qatargas consortium for equipping their big LNG carriers (Q-Max and Q-Flex class) with ME-series, electronically controlled, low-speed combustion reciprocating engines. Initially, the application of Dual-Fuel engines with an option of running on the vaporized gas has been considered. However, due to the complexity of the gas supply system and lack of experience in exploiting such systems, the idea was abandoned. Ultimately, twin-engine drives with engines running on liquid fuels have been chosen: $6 \mathrm{~S} 70 \mathrm{ME}-\mathrm{C}$ and 7S70ME-C for Q-Flex and Q-Max classes respectively. The gas vaporized in them was liquefied and re-directed back to the tanks.

Introducing in the recent years to main propulsion of ships slow-speed, two-stroke, dual-fuel engines prompted Qatargas consortium to reconsider the concept of using such engines for $\mathrm{Q}_{\max }$ and $\mathrm{Q}_{\mathrm{flex}}$ class units. A decision has been taken to adjust two engines of the main drive 7S70MEC7, on one of the Q-Max class carriers being already in service, to be capable of combusting natural gas (7S70ME-GI version). It required the adaptation of the engine for gas combustion using a gas supply system in the engine head shown in Fig. 3 and the development of the engine fuel supply system with fuel gas.

In order to achieve the engine's thermal efficiency of $50 \%$ it must be ensured that the gas flowing to the engine is under the pressure between 15 and $30 \mathrm{MPa}$. With engine's nominal load, pressure of the gas reaches up to $30 \mathrm{MPa}$, while with lower loads, the gas pressure decreases linearly to reach $15 \mathrm{MPa}$ with $30 \%$ of the load. Therefore, engine's gas supply system requires application of dedicated compressor units. That is why the modernized ship has been equipped with special high-pressure pumps. An engine's high-pressure gas supply system used on that unit can be seen in Fig. 4.

In order to supply the engine with well-prepared gas fuel, a series of modifications are essential to be made. In the cargo tanks, additional supply pumps are installed 2 . These pumps are connected to the existing pipeline for pumping gas to cool down the tanks. It enables the transportation of the liquefied gas to the buffer tank by means of supply pumps 2 as well as spray pumps 3. Booster pumps, placed directly within the buffer tank, pump LNG to the suction pipeline 
of the high-pressure pumps 5. Gas pressure at its pressing is regulated by the means of adjusting sprayers got, quite often, melted. After consultation in this regard with the engines manufacturer, new sprayers were manufactured, this time made of tin-coated steel and this solved the problem straightaway.

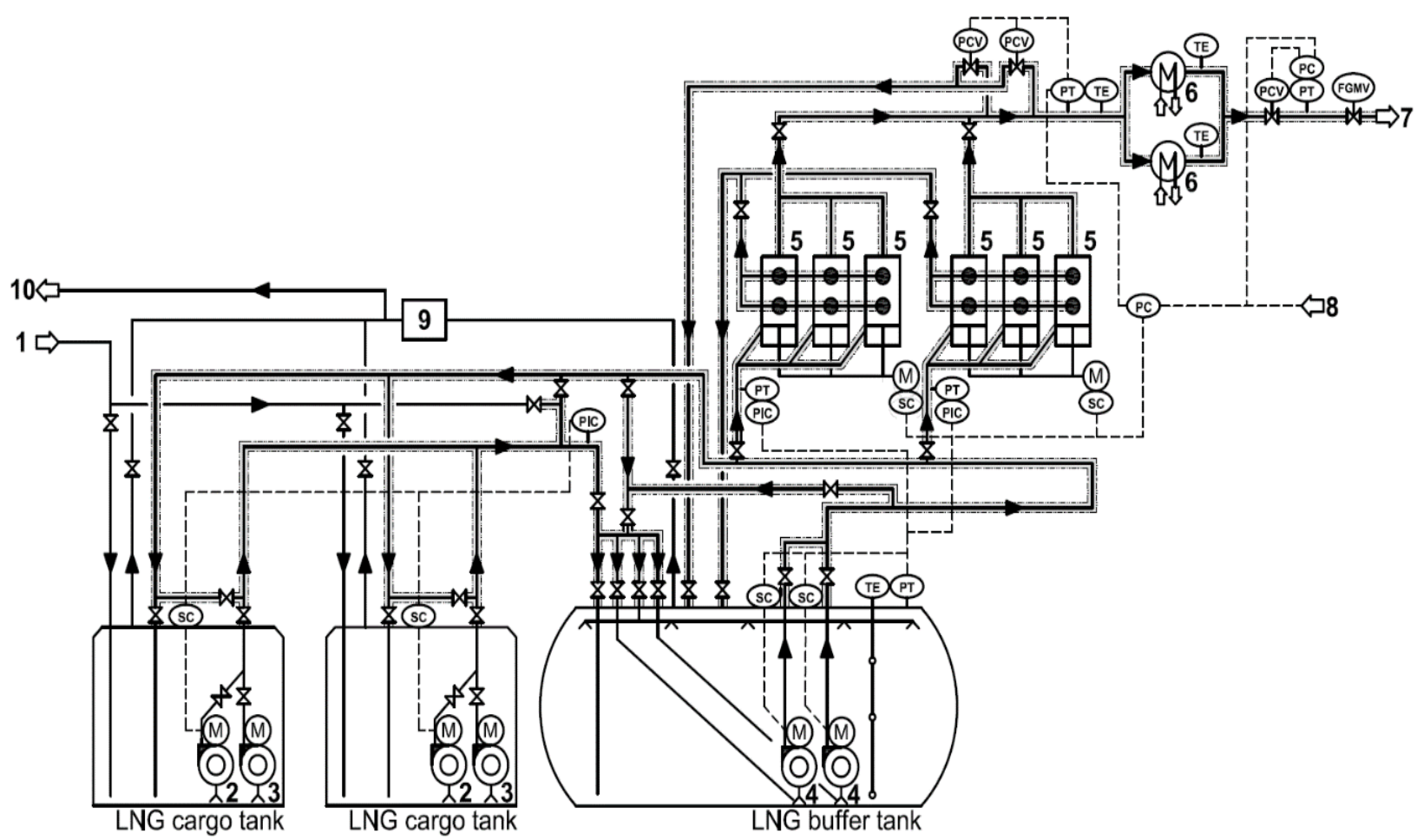

Fig. 4. Low-speed engine's natural gas supply installation [3]; 1 - reliquefaction plant; 2 - supply pump; 3 - spray pump; 4 - booster pump; 5 - high-pressure pump; 6 - heater; 7 - ME-GI main engine; 8 - ME-GI main engine control unit; 9 - vaporized natural gas manifold; 10 - to reliquefaction plant; $S C$ - variable frequency drive; PIC-pressure indicating controller; PT-pressure transmitter; PC-pressure controller; PCV-pressure control valve; TE-temperature indicator; FGMV-fuel gas master valve

The adjustment of the engines of the main drive, so that they can run on the vaporized gas, had as one of its aims lowering the costs of operating a ship. In recent years, the cost of producing an energy unit from an engine running on liquid fuel has exceeded threefold the cost of producing the same amount of energy from an engine operating on natural gas (Fig. 1).

After completing the modernization of the Q-max class vessel so as to adjust it to operate on gas fuel as its main drive, the ship's fuel consumption has been measured with various engine loads and the minimal amount of pilot heavy fuel, amounting to ca. $5 \%$ of the volume. The basic results of the measurements are presented in Tab. 2, and a broader description of the tests carried out [3].

The rotation speed of the pump. Then, gas, compressed to the required pressure, goes to the heater 6, where the right temperature is provided by the heating medium - the water-glycol mixture. It enables vaporization and heating the gas up to the temperature of 45 degrees C. Finally, the gas goes to the very engine where it is combusted.

Before introducing the modifications, the vaporized gas would be normally directed via the pipeline 10 for re-liquefaction. Once the installation of the engine fuel supply was expanded, an opportunity has arisen that the gas can be taken directly from the liquefying installation by the pipeline 1 and directed to the buffer tank.

High standards demanded from the LNG delivery installations made it obligatory to use double-walled pipelines. The safety system constantly collects and samples the air from between 
the walls inside the pipeline. In case of detection of gas particles in there, the engine's gas supply system is immediately switched off and the quick-closing valves are cut off. The automation enables a smooth transition from gas to liquid fuel without any stoppages in the engine's operation.

Once the adjusting works were completed and attempts to run the engines on gas were made, some operating issues started to appear, especially at the beginning; among other things, injector sprayers were melted. After consultation in this regard with the engines manufacturer, new sprayers were manufactured, this time made of tin-coated steel and this solved the problem straightaway.

The adjustment of the engines of the main drive, so that they can run on the vaporized gas, had as one of its aims lowering the costs of operating a ship. In recent years, the cost of producing an energy unit from an engine running on liquid fuel has exceeded threefold the cost of producing the same amount of energy from an engine operating on natural gas (Fig. 1).

After completing the modernization of the Q-max class vessel so as to adjust it to operate on gas fuel as its main drive, the ship's fuel consumption has been measured with various engine loads and the minimal amount of pilot heavy fuel, amounting to ca. $5 \%$ of the volume. The basic results of the measurements are presented in Tab. 2, and a broader description of the tests carried out [3].

Tab. 2. Main engines' consumption for gas fuel and pilot dose of liquid fuel during sea trials

\begin{tabular}{|c|c|c|}
\hline Engine load [\%] & $\begin{array}{c}\text { Pilot oil consumption } \\
{[\mathrm{t} / 24 \mathrm{~h}]}\end{array}$ & $\begin{array}{c}\text { Natural gas consumption } \\
{[\mathrm{t} / 24 \mathrm{~h}]}\end{array}$ \\
\hline 60 & 14.16 & 69.31 \\
\hline 75 & 15.40 & 84.10 \\
\hline 85 & 17.86 & 100.18 \\
\hline 90 & 16.66 & 108.48 \\
\hline 100 & 15.46 & 117.14 \\
\hline
\end{tabular}

For the purpose of analysis and calculation of the costs of running the main drive on fuel, an assumption has been made that the ordinary conditions of operating a vessel are with the main engines' load at the level of $85 \%$. The parameters of the operation of an engine with such a load can be found in Tab. 2.

While run on natural gas, load amounting to $85 \%$ for both engines of the main drive and the pilot dose of heavy fuel on a minimal level (ca. 5\%), the heavy fuel consumption for both engines amounted to 17.86 tons and for natural gas -100.18 tons. Based on the fuel prices from recent years, shown in the Fig. 1, costs of running the vessel's engines for 24 hours can be estimated to be around US \$27,153.

When running the engines with the $85 \%$ load only on the liquid fuel, two $7 \mathrm{~S} 70 \mathrm{ME}$ engines consume approximately 140 tons of heavy fuel daily what generates cost of US $\$ 44,800$.

This comparative analysis shows that the cost of operating a gas-powered (LNG) unit with the minimum required heavy fuel dose is almost twice as low as when supplied with only heavy liquid fuel (HFO).

\section{Summary}

At present, the construction costs of ships equipped with dual-fuel engines are much higher to those equipped with conventional engines. Moreover, a significant problem for ships other than gas carriers, which can use the transported cargo for the engines, is limited possibility of 
bunkering gas fuel in many ports. However, in recent years there has been a significant increase in the number of LNG bunkering stations in ports, including our country.

It seems that the choice of the propulsion system for the newly-built large LNG gas carriers will be directed to dual-fuel, two-stroke engines with the highest efficiency, in addition to the already commonly used dual-fuel four-stroke engines. This may be determined by the constantly changing prices of liquid fuels, with the stabilization and much lower price of gas. In addition, the increasingly restrictive environmental protection regulations currently applicable in the special areas of ECA (Emissions Control Areas), which aim to reduce the emission of harmful substances into the atmosphere, may have a major impact on this. Introduced from 1 January 2020 Annex VI of the Marpol Convention imposes an obligation to use liquid fuels for the propulsion of ships with sulphur content reduced to $0.5 \%$. In this situation, gas combustion in engines will ensure compliance with all, even the most restrictive regulations and standards.

Two-stroke, dual-fuel engines operating in gas mode meet all emission standards without the need for additional, expensive exhaust gas cleaning systems or scrubbers, which usually have large dimensions and take up a considerable space of the ship, often at the expense of the transported cargo. All this speaks for the use of these engines on large LNG and LPG gas carriers. Experiences related to the operation of a two-stroke dual-fuel combustion engine on an ISLA BELLA container can become the beginning of the widespread use of these drives also on other ships than gas carriers.

\section{References}

[1] Giernalczyk, M., Analysis possibilities of cost reduction related to boil-off fuel gas being carried on LNG Gas Carriers, PAN Journal of KONES Powertrain and Transport, European Science Society of Powertrain and Transport Publication, Warsaw 2007.

[2] Giernalczyk, M., Analysis possibilities of the application of dual fuel engines as a main propulsion on LNG Gas Carriers, PAN Journal of KONES Powertrain and Transport, European Science Society of Powertrain and Transport Publication, Warsaw 2008.

[3] Giernalczyk, M., Łoński, F., Kaniak, W., Ways of adjusting the two-stroke diesel engine to be run on liquefied natural gas, New trends in production engineering, Vol. 1, Is. 1, pp. 317-324.

[4] Linwood, J., Jong-Pil, Ha, Kjeld, A., Rene, S.L., LNG Gas Carrier with High-pressure Gas Engine Propulsion Application, GasTech, Dubai, United Arab Emirates 2006.

[5] LNG Carrier Propulsion by ME-GI Engines and/or Reliquefaction, MAN Diesel \& Turbo, Denmark 2003.

[6] LNG Carriers with ME-GI Engine and High-Pressure Gas Supply System, MAN Diesel \& Turbo, 5510-0026-04ppr, Denmark 2014.

[7] MAN, S70 ME-GI Project Guide, $2^{\text {nd }}$ Edition, October 2005.

[8] Significant Ships of 2013-2018, A publication of the Royal Institution of Naval Architects, London UK 2013-2018.

[9] www.dnvgl.com/maritime/lng/current-price-development-oil-and-gas.html.

[10] www.wingd.com/en/documents/rt-flex50df/engine-operation/operation-manual-(om).

[11]www.wingd.com/en/documents/general/brochures/x-df-faq-brochure.pdf/. 